\title{
Ionospheric Disturbances Over Indonesia and Their Possible Association With Atmospheric Gravity Waves From the Troposphere
}

\author{
Tadahiko OGAWA, Yuichi OTSUKA, Kazuo SHIOKAWA \\ Solar-Terrestrial Environment Laboratory, Nagoya University, Toyokawa, Japan \\ Akinori SAITO and Michi NISHIOKA \\ Department of Geophysics, Graduate School of Science, Kyoto University, Kyoto, Japan \\ (Manuscript received 2 November 2005, in final form 18 February 2006)
}

\begin{abstract}
As part of the CPEA (Coupling Processes in the Equatorial Atmosphere) project, we have been conducting ground-based optical and radio observations of the ionosphere and thermosphere at Kototabang in Indonesia, Japan, and Australia. First, this paper gives a brief overview of some results, paying special attention to $100-1000 \mathrm{~km}$ scale plasma disturbances in the $F$ region ionosphere, i.e., medium-scale traveling ionospheric disturbances (MSTIDs) and plasma bubbles. MSTIDs over the equator are observed within and in the south of the $F$ region equatorial anomaly crest and have, on the average, a phase velocity of $300 \mathrm{~m} \mathrm{~s}^{-1}$ toward the south, a period of $40 \mathrm{~min}$, and a wavelength of $700 \mathrm{~km}$. Plasma bubbles move to the east at $\sim 100 \mathrm{~m} \mathrm{~s}^{-1}$, have a scale of about $100 \mathrm{~km}$ with spacings of $200-250 \mathrm{~km}$, and are embedded within plasma structures with a scale of about $1000 \mathrm{~km}$. Interestingly, giant plasma bubbles can be simultaneously detected at lower midlatitudes in southern and northern hemispheres that are connected by the geomagnetic field line, and are very identical in appearance in the both hemispheres. Then, we present newly-obtained characteristics of equatorial ionospheric scintillations of 1.6$\mathrm{GHz}$ GPS radio waves associated with plasma bubbles. Continuous scintillation observations for two years at Kototabang indicate that the scintillations appear predominantly from sunset to midnight in equinoctial months. Such a seasonal variation is also recognized from a statistical study of bubble occurrences over the Philippines, Singapore, and Indonesia. To investigate possible dynamical coupling between the ionosphere/thermosphere and troposphere over the equator, we compare the scintillation (bubble) activity and Earth's brightness temperature variation over the Indian Ocean measured by meteorological satellites. The results indicate that there can exist meaningful correlations between the scintillation occurrence and tropospheric disturbance at $80^{\circ}-95^{\circ} \mathrm{E}$ longitudes, i.e. $5^{\circ}-20^{\circ}$ west of Kototabang. Possible processes to seed plasma bubbles are discussed.
\end{abstract}

\section{Introduction}

A variety of plasma disturbances appear in the equatorial $F$ region ionosphere. The most spectacular and attractive phenomenon at night is plasma bubbles that are deep deple-

Corresponding author: Tadahiko Ogawa, SolarTerrestrial Environment Laboratory, Nagoya University, Toyokawa, Aichi 442-8507, Japan.

E-mail: ogawa@stelab.nagoya-u.ac.jp

(C) 2006, Meteorological Society of Japan tions in plasma. Bubbles are known to be generated in the bottomside of the $F$ region after sunset of the ionosphere through the RayleighTaylor (R-T) plasma instability, and are necessarily accompanied by electron density irregularities with various scale sizes causing spread echoes on ionograms ("equatorial spread- $F$ "), radar backscatter at HF-VHF bands, and scintillations of satellite signals. They have been well monitored from the ground by using radio and optical methods (Kelley 1989), and from 
satellites equipped with an in situ plasma probe (e.g., Oya et al. 1986) and an airglow imager (e.g., Kelley et al. 2003; Ogawa et al. 2005). Many issues, however, yet remain to be solved before a full understanding of the electrodynamics related to bubbles and spread- $F$ (e.g., Abdu 2004). One of the outstanding questions is the seeding processes of plasma perturbations that ultimately develop into bubbles through the R-T instability.

Many researchers have experimentally suggested that atmospheric gravity waves (AGWs) propagating in the equatorial thermosphere play an important role in seeding bubbles and spread-F (e.g., Kelley et al. 1981; Hysell et al. 1990; McClure et al. 1998; Lin et al. 2005). Medium-scale traveling ionospheric disturbances (MSTIDs) with horizontal scales of 200-800 km are believed to be an ionospheric manifestation of AGWs. Kelley et al. (1981) found that spread- $F$ irregularities observed by a VHF radar show clear association with a sinusoidal oscillation of the altitude of the bottomside $F$ layer, and suggested that the oscillation is initiated via the spatial resonance mechanism (Whitehead 1971; Beer 1973), i.e. when phase velocity of MSTIDs matches that of $\mathbf{E} \times \mathbf{B}$ plasma drift velocity (see also Röttger 1981). From satellite observations, Singh et al. (1997) showed that bubbles develop from wavy ion density structures with east-west wavelengths of $150-800 \mathrm{~km}$ in the bottomside $F$ layer. Tsunoda (2005 and references therein) have stressed that development of large-scale $(\sim 400 \mathrm{~km})$ wavy structure in the bottomside $F$ layer is necessary and sufficient for equatorial spread- $F$ (bubble) occurrence, and that variability in the structure development may contribute to day-to-day variability of spread- $F$. Thus MSTIDs seem to play a key role in initiating bubbles. Then the question is what the origins of MSTIDs (or AGWs) are. Röttger (1977, 1981) suggested that MSTIDs, due to AGWs perhaps generated by convective activity in the intertropical convergence zone, have a reasonable influence on large-scale structure of spread- $F$ irregularities, accordingly, plasma bubbles (see also McClure et al. 1998).

A 6-year research project "Coupling Processes in the Equatorial Atmosphere" (CPEA) started in September 2001 aims to understand basic processes of the dynamical and electrodynami- cal couplings occurring in the equatorial lower, middle, and upper atmosphere (Fukao 2006). As part of CPEA, we have been conducting ground-based optical and radio observations of the ionosphere and thermosphere over Sumatra in Indonesia, Sata and Shigaraki in Japan, and Darwin in Australia. In this paper we first present brief overviews of nighttime MSTIDs detected at Kototabang in Sumatra with an all-sky imager and of giant geomagnetic-conjugate plasma bubbles simultaneously detected in Japan and Australia with all-sky imagers, and show that the ionospheric plasmas near the equator are disturbed and structured with spatial scales of 100$1000 \mathrm{~km}$. Then we show characteristics of equatorial ionospheric scintillations (induced by plasma bubbles) of radio waves from the Global Positioning System (GPS) satellites received at Kototabang, Sumatra, in 2003 and 2004, and stress that the scintillation occurrences are well coincident with short-scale (a few $\mathrm{km}$ to tens of $\mathrm{km}$ ) fluctuations of ionospheric total electron content measured in the Philippines, Singapore, and Indonesia. Finally, to investigate possible dynamical couplings between the ionosphere/thermosphere and troposphere over the equator, we compare the scintillation activity and Earth's infrared brightness temperature measured by meteorological satellites. The results suggest that there can exist some correlations between the scintillation (bubble) occurrence and tropospheric disturbance over the Indian Ocean.

\section{Observations}

\subsection{Traveling ionospheric disturbances over Kototabang}

We have been conducting OI 630-nm airglow measurements at night by means of an all-sky $\mathrm{CCD}$ imager at Kototabang $\left(0.20^{\circ} \mathrm{S}, 100.32^{\circ} \mathrm{E}\right.$; geomagnetic latitude $\simeq \operatorname{dip}$ latitude $10.36^{\circ} \mathrm{S}$ ) to investigate plasma disturbances in the equatorial ionospheric $F$ region (Shiokawa et al. 2006). The $630-\mathrm{nm}$ airglow intensity is proportional to the electron density at around $250 \mathrm{~km}$ altitude below the bottomside of the $F$ region, enabling us to know two-dimensional electron density distribution in the horizontal plane at around this altitude through an analysis of all-sky image data. Ionospheric disturbances with horizontal scales of $100 \mathrm{~km}$ or more are 


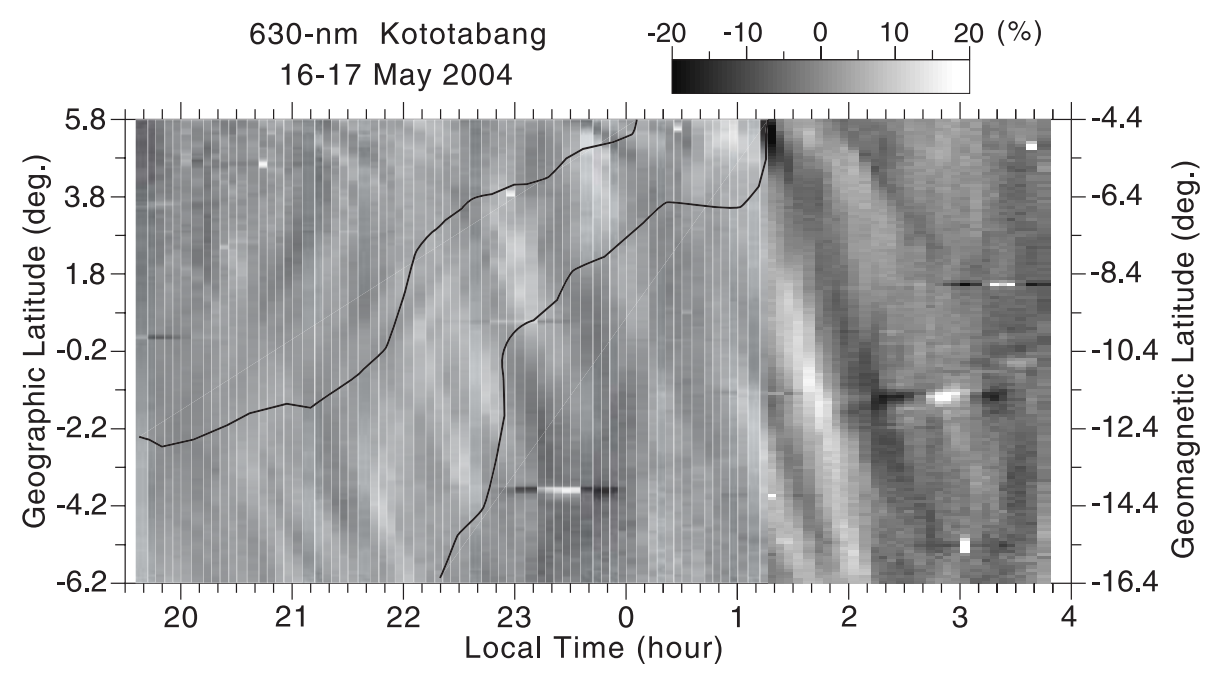

Fig. 1. Keogram of OI 630-nm airglow intensity variation (deviation in \% from 1-hour running average) in time-geographic latitude coordinates at $100.3^{\circ} \mathrm{E}$ constructed from all-sky images at Kototabang $\left(0.20^{\circ} \mathrm{S}, 100.32^{\circ} \mathrm{E}\right)$ on the night of 16 May 2004 (from Shiokawa et al. 2005). Corresponding geomagnetic latitudes are shown in the right ordinate. Northern and southern boundaries of the equatorial anomaly crest are indicated by the solid curves. Sporadic narrow horizontal structures are due to stars.

easily recognized as wavy structures in the image.

630-nm airglow intensity maps with $512 \times 512$ pixels were obtained every $4.5 \mathrm{~min}$ with an exposure time of $105 \mathrm{~s}$. Using these maps we calculated a deviation of airglow intensity in each pixel. Here the deviation $\Delta I(t)$ (in \%) is defined as $\left(I(t)-I_{0}\right) / I_{0}$ where $I(t)$ is the absolute intensity (in units of Rayleighs) at time $t$ and $I_{0}$ is the one-hour running average of $I(t)$. Then the deviations were plotted on geographic coordinates by assuming an emission altitude of $250 \mathrm{~km}$ to generate a $\Delta I(t)$ map (keogram) in time-latitude coordinates at the longitude of Kototabang. One example of the keograms on the night of 16 May 2004 is shown in Fig. 1 (Shiokawa et al. 2005). The oblique white and dark striations with negative slope, which indicates the southward movement of the bright and dark airglow regions, are clearly discerned in the figure. In detail, the striation starts to appear in the left bottom corner, and then the starting point of each striation shifts toward the north (equator) with time. Such a shift coincides well with the northward movement of the southern equatorial anomaly crest with enhanced electron density (the northern and southern boundaries of the crest deter- mined from the $I(t)$ data are indicated in Fig. 1 by the solid curves). After $0000 \mathrm{LT}$ the striations extended to the whole latitudes $\left(6.2^{\circ} \mathrm{S}-\right.$ $5.8^{\circ} \mathrm{N}$; about $1200 \mathrm{~km}$ ) covering the field-ofview (FOV) of the imager, while the crest region moved further toward the magnetic equator. The striations disappeared after 0300 LT. These facts strongly suggest that the bright and dark airglow regions associated with the northward-moving equatorial anomaly crest propagated toward the south as a wave.

The statistical analysis of many events by Shiokawa et al. (2005) indicates the following: the waves (1) are observed within and in the south of the equatorial anomaly crest, (2) have phase fronts aligned predominantly in the east-west direction, (3) propagate southward with a phase velocity of $310 \pm 110 \mathrm{~m} \mathrm{~s}^{-1}$ and a period of $40 \pm 15 \mathrm{~min}$ (therefore, with a wavelength of about $700 \mathrm{~km}$ ), and (4) appear during the May-June period with high occurrence rate of $53 \%$ and in other months with a rate of about $20 \%$. Interestingly there was a case in which the imager detected simultaneously waves and eastward-moving $\left(\sim 90 \mathrm{~m} \mathrm{~s}^{-1}\right)$ plasma bubbles. Item 3 means that the waves are categorized as a class of MSTIDs. The origin of the waves is not clear, but attributable to AGWs coming 


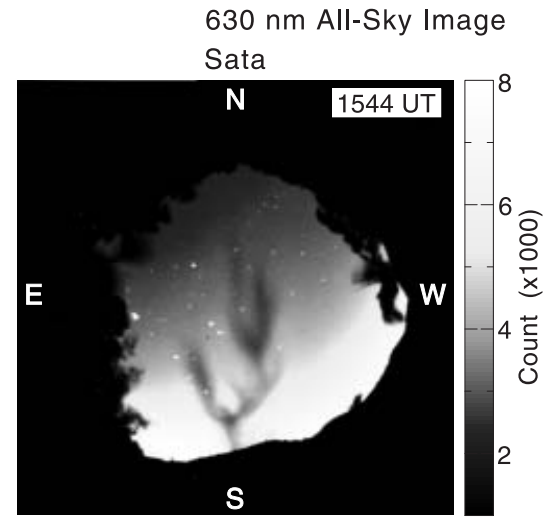

12 November 2001

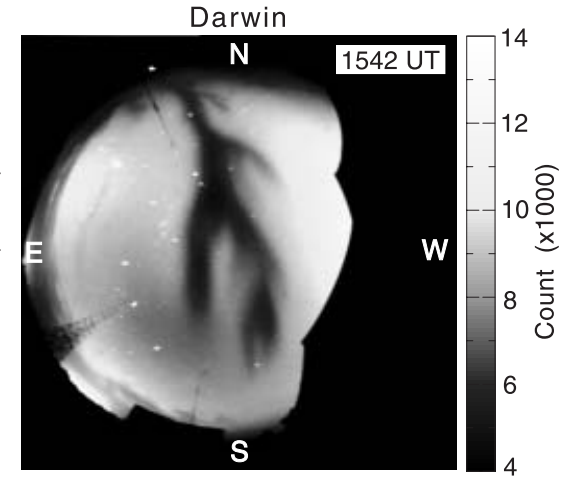

Fig. 2. OI 630-nm all-sky images almost simultaneously obtained with two imagers at (left) Sata and (right) Darwin on the night of 12 November 2001 (from Otsuka et al. 2002). LT $=\mathrm{UT}+9$ hours.

from below to disturb the equatorial thermosphere and ionosphere. Notice that plasmas in the equatorial $F$ region show generally maximum (minimum or no) response to an AGW propagating in the meridional (zonal) direction (Hooke 1970). This can explain why the 630$\mathrm{nm}$ airglow structures tend to have phase fronts aligned in the east-west direction (item 2 ) and to propagate in the north-south direction (item 3), and suggests that it is impossible to detect zonally-propagating AGWs from the current airglow measurements.

\subsection{Geomagnetic-conjugate plasma bubbles}

Well-developed plasma bubbles can reach $1000 \mathrm{~km}$ altitude or more in the topside ionosphere over the magnetic equator. Otsuka et al. (2002) were the first to show that bubble structures observed with a 630-nm all-sky imager at Sata, Japan $\left(31.0^{\circ} \mathrm{N}, 130.7^{\circ} \mathrm{E}\right)$ were almost identical to those obtained with an all-sky imager at Darwin, Australia $\left(12.4^{\circ} \mathrm{S}, 131.0^{\circ} \mathrm{E}\right)$ that is close to the geomagnetic-conjugate point of Sata. Figure 2 displays all-sky images taken almost simultaneously at Sata and Darwin on the night of 12 November 2001 (Otsuka et al. 2002). Plasma bubbles are identified in both images as the dark regions, nearly aligned in the north-south direction with a little tilt to the west with increasing latitude, with low airglow intensity and east-west scale sizes of 40 $100 \mathrm{~km}$. The bubbles moved eastward at about $100 \mathrm{~m} \mathrm{~s}^{-1}$ without changing much their struc- tures. As can be seen in the figure, the twodimensional shapes of the bubbles are surprisingly identical each other, though the intensity is different. This fact indicates that the plasma depletion regions with maximum altitude of $\sim 1700 \mathrm{~km}$ over the magnetic equator elongate along geomagnetic field lines. Similar geomagnetic-conjugate bubble phenomena were also reported by Shiokawa et al. (2004).

Until now, ground- and satellite-based observations have revealed detailed characteristics of plasma bubbles. Kelley et al. (2003) reported coordinated observations of bubbles with airglow imagers on the TIMED satellite in a near circular orbit at $630-\mathrm{km}$ altitude and the ground, and found that bubble structures seen in both the airglow maps were consistent with those explored previously by means of radars and numerical simulations. However, the relationship between bubble phenomena in a limited area (as observed by, for example, groundbased all-sky imagers) and large-scale ( $\geq 1000 \mathrm{~km}$ ) background ionospheric structure, in which bubbles are located, is still unclear. Ogawa et al. (2005) have compared, for the first time, geomagnetic-conjugate plasma bubbles simultaneously observed at Shigaraki, Japan $\left(34.8^{\circ} \mathrm{N}, 136.1^{\circ} \mathrm{E}\right)$ and Darwin with nearsimultaneous two-dimensional global-scale ( $\sim 10,000 \mathrm{~km}$ in the east-west direction) ionospheric structures imaged by the IMAGE satellite (Sagawa et al. 2003). Figure 3a shows an image at low and equatorial latitudes taken at 


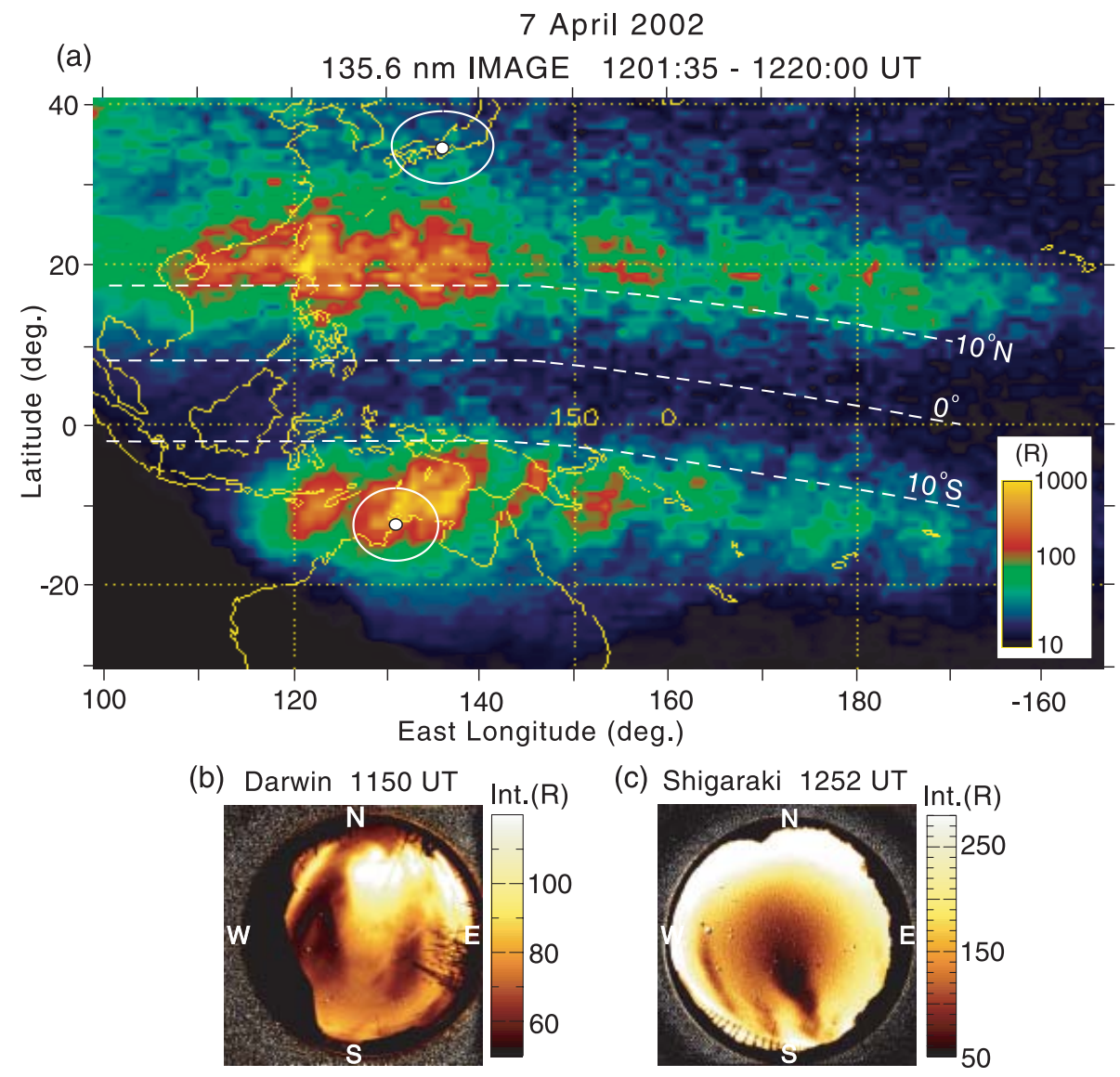

Fig. 3. (a) OI 135.6-nm IMAGE image in geographic coordinates at 1201:35-1220:00 UT on 7 April 2002 (from Ogawa et al. 2005). Geomagnetic latitudes are shown by dashed curves. Positions of Shigaraki and Darwin are marked by dots. Shigaraki and Darwin imager FOVs, with a diameter of $1000 \mathrm{~km}$ at $250 \mathrm{~km}$ altitude, are also indicated by white circles. (b) OI 630-nm all-sky image at 1150 UT at Darwin on 7 April 2002. Bright area in the northeastern sky is due to clouds. (c) Same as (b), but at 1252 UT at Shigaraki.

1201:35-1220:00 UT on 7 April 2002 with an OI 135.6-nm imager on IMAGE at $\sim 7$ earth radii. As a first approximation the 135.6-nm emission intensity originates mostly from a $100-\mathrm{km}$ altitude range centered near the $F$ region peak (Sagawa et al. 2003). Therefore Fig. 3a is regarded as a snapshot of twodimensional electron density distribution in the horizontal plane near the $F$ region peak. The wavy electron density structures with a typical east-west wavelength of about $1000 \mathrm{~km}$ are observed at hours between local sunset and midnight over a total longitudinal distance of $\sim 10,000 \mathrm{~km}$ ( $\sim 6$ hours in local time). According to Sagawa et al. (2003), the structures exist within the wide band-like airglow regions that correspond to the northern and southern equatorial anomaly crests. They are roughly inphase in both hemispheres, which suggests that the structures are geomagnetically conjugate, and move toward the east at $\sim 100 \mathrm{~m} \mathrm{~s}^{-1}$. Figures $3 \mathrm{~b}$ and $3 \mathrm{c}$ exhibit 630-nm images taken at $1150 \mathrm{UT}$ (2050 LT) and 1252 UT (2152 LT) at Darwin and Shigaraki, respectively. The multiple plasma bubbles (dark airglow regions) in the Darwin all-sky image are located within the southern equatorial anomaly crest, while those in the Shigaraki image are situated near the northern edge of the northern crest.

Analyzing the successive IMAGE pictures and all-sky images, Ogawa et al. (2005) have found the following: (1) plasma bubbles de- 
tected with the all-sky imagers move to the east at $\sim 100 \mathrm{~m} \mathrm{~s}^{-1}$ with spacings of $200-250 \mathrm{~km}$ (this movement is consistent with that of the $1000-\mathrm{km}$ scale structures in Fig. 3a). (2) The bubbles observed with the all-sky imagers and satellite imager are embedded within mediumto large-scale (a few hundreds to $1000 \mathrm{~km}$ in the east-west direction) wavy structures of the electron density in the equatorial anomaly crests. (3) Some bubbles are located near the crests associated with the wavy structures. These results suggest that the generation and evolution of plasma bubbles are closely related to those of the medium- to large-scale plasma structures.

\subsection{Ionospheric scintillations of GPS radio waves}

Plasma bubbles are necessarily accompanied by electron density irregularities with various spatial scales. Field-aligned irregularities (FAIs) with a few meter scales within bubbles cause coherent VHF radar backscatter (e.g., Woodman and LaHoz 1976; Fukao et al. 2004), and those with a few hundred meters induce ionospheric scintillations when a GPS radio wave penetrates horizontally-moving FAI regions (Beach and Kintner 1999). Basu et al. (1983) made a direct comparison between plasma depletions detected with an in situ probe and VHF (257 MHz) and $\mathrm{GHz}(1.54 \mathrm{GHz})$ scintillations in the equatorial region. From simultaneous observations of $3.2-\mathrm{m}$ scale FAIs in the $F$ region with the $47-\mathrm{MHz}$ Equatorial Atmosphere Radar (EAR) and plasma bubbles with the 630-nm all-sky imager at Kototabang, Otsuka et al. (2004) have found that FAIs are confined within plasma bubbles. These observations indicate the availability of a GPS scintillation technique to know plasma bubble occurrence throughout day, season, and year (e.g., Aarons et al. 1983; Kelley et al. 2002).

Since January 2003, we have been monitoring ionospheric scintillations at Kototabang by means of three $1.5754-\mathrm{GHz}$ GPS receivers located with mutual distances of 116, 127, and $152 \mathrm{~m}$ to know drift velocity of FAIs (Otsuka et al. 2006). One of the important parameters to represent scintillation activity is the scintillation index $S_{4}$ that is defined as the normalized standard deviation signal intensity, i.e. $S_{4}^{2}=\left(\left\langle I^{2}\right\rangle-\langle I\rangle^{2}\right) /\langle I\rangle^{2}$, where $I$ is the signal intensity and the angle brackets denote the ensemble average of the enclosed quantity. We calculated $S_{4}$ every one minute by using data from one of the receivers that provide signal intensity with a sampling rate of $20 \mathrm{~Hz}(50 \mathrm{~ms})$. When signals from multiple GPS satellites were simultaneously received, the highest $S_{4}$ of all the $S_{4}$ values was selected. The $S_{4}$ data with satellite zenith angles $\leq 60^{\circ}$ were adopted to know the scintillation occurrence within the circular area with a diameter of $520 \mathrm{~km}$ at $300 \mathrm{~km}$ altitude over Kototabang.

Figure 4 displays $S_{4}$ variations in day-local time coordinates in 2003 and 2004 . The $S_{4}$ values less than about 0.4 are due to background noise. The vertical black portions represent no observations due to instrumental problem that happened sporadically (see Fig. 6 in detail). Such a problem, however, is not important for the following discussion on the scintillation activity characteristics. Figure 4 indicates that the scintillations appear predominantly in equinoctial months, i.e. in March-April and September-October, and between sunset ( 2000 LT) and 0100 LT in March-April and between 2000 and 2300 LT in SeptemberOctober. These facts are generally consistent with previous equatorial scintillation observations (e.g., Su. Basu and S. Basu 1985). We note that the scintillation occurrences have periods of a few to 10 days (see Fig. 8) and that the scintillation activity is higher in MarchApril than September-October. Such a seasonal asymmetry is also discerned in previous studies (e.g., Su. Basu and S. Basu 1985; Basu et al. 1988). The reason of the asymmetry is unknown at this stage. The seasonal pattern of equatorial scintillations (bubbles) is known to depend on longitude. More data acquisition is needed to clarify detailed seasonal pattern at Kototabang which is located in the transition region between the Atlantic/Indian Ocean and Pacific Ocean sectors.

Figure 4 indicates a few scintillation events between late May and early August in both 2003 and 2004. We have examined geomagnetic $K p$-indices in these months (World Data Center for Geomagnetism, Kyoto, Japan; http://swdcdb .kugi.kyoto-u.ac.jp/) to find that the geomagnetic activities are weaker in 2004 than 2003 and that some scintillation events seem to attribute to geomagnetic disturbances (i.e., high 


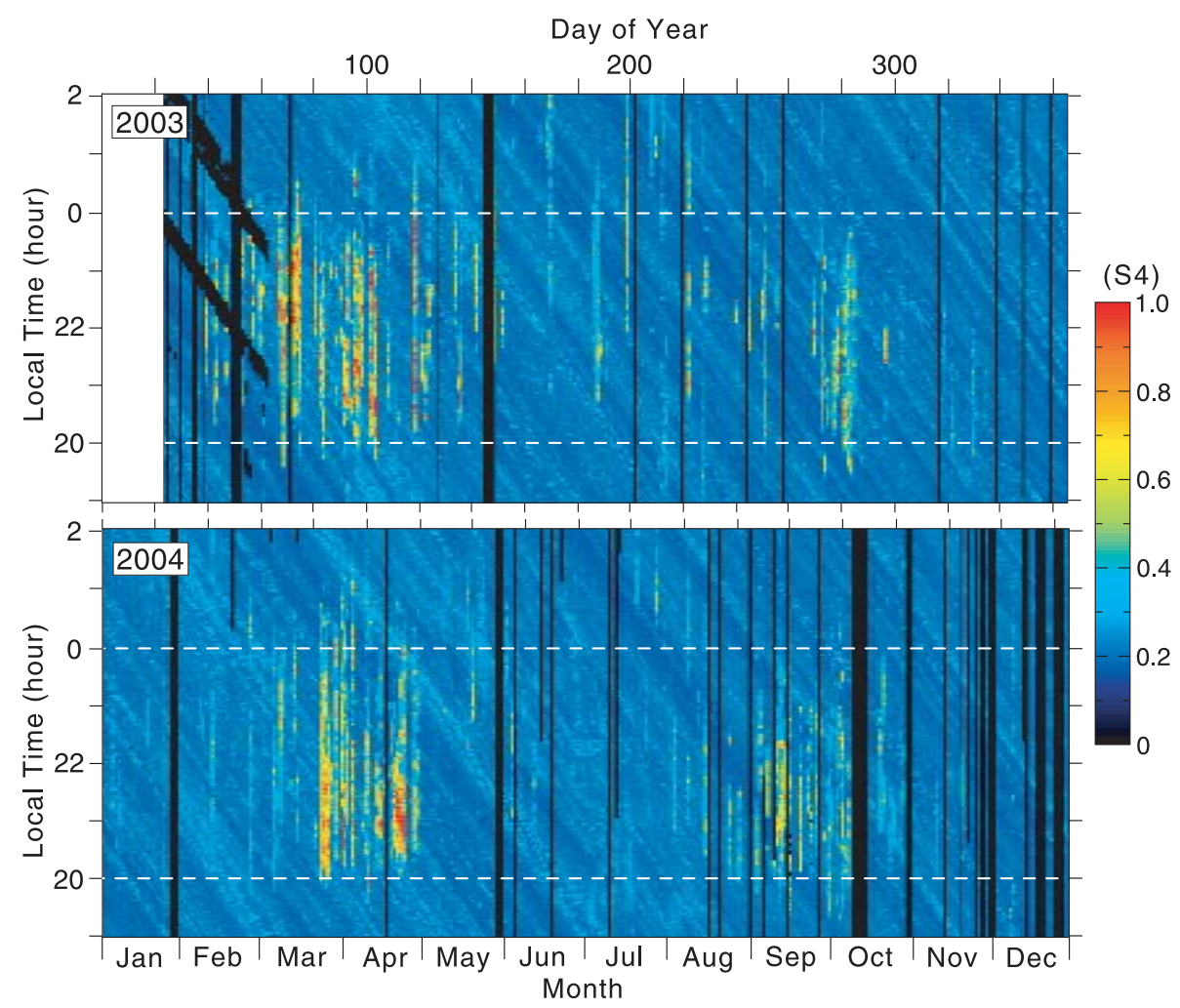

Fig. 4. Variations of GPS scintillation index $\left(S_{4}\right)$ in day-local time coordinates observed at Kototabang in 2003 and 2004. $S_{4}$ values less than about 0.4 are due to background noise. Vertical black portions represent no observations due to instrumental problem.

$K p$ 's). In the future we need more investigations to clarify the detailed relationship between the scintillations in May-August and geomagnetic conditions.

\subsection{Ionospheric scintillations and TEC disturbances}

Plasma bubbles are known to appear between sunset and later hours after midnight, while the GPS scintillations disappear at around midnight as shown in Fig. 4: the latter fact means that electron density irregularities causing the scintillations do not exist after midnight. The GPS scintillations are caused by FAIs with a spatial scale of about $350 \mathrm{~m}$ (first Fresnel size) within and around bubbles. Therefore Fig. 4 can be regarded as a proxy of the plasma bubble occurrences before midnight over Kototabang. To reinforce this, we compare the scintillation occurrences and small-scale ionospheric disturbances over India, Southeast Asia, and Western Pacific. To identify such ionospheric disturbances, we use GPS total electron content (TEC) data collected at five International GNSS Service (IGS) stations in these regions; i.e. at Guam [GUAM] $\left(13.6^{\circ} \mathrm{N}\right.$, $\left.144.9^{\circ} \mathrm{E}\right)$, the Philippines [PIMO] $\left(14.6^{\circ} \mathrm{N}\right.$, $\left.121.1^{\circ} \mathrm{E}\right)$, Singapore [NTUS] $\left(1.3^{\circ} \mathrm{N}, 103.7^{\circ} \mathrm{E}\right)$, Indonesia [SAMP] $\left(3.6^{\circ} \mathrm{N}, 98.7^{\circ} \mathrm{E}\right)$, and India [IISC] $\left(13.0^{\circ} \mathrm{N}, 77.6^{\circ} \mathrm{E}\right)$, which are located at the similar dip latitude $\left( \pm 7^{\circ}\right)$. The TEC data, sampled every $30 \mathrm{~s}$, from each station were processed to obtain the "Rate of TEC Index" (ROTI in units of TECU $\mathrm{min}^{-1}$ : one TECU $=10^{16}$ electrons $\mathrm{m}^{-2}$ ). In this paper ROTI is defined as a standard deviation of temporal variation of TEC for $5 \mathrm{~min}$. ROTI variation is caused by TEC fluctuations with spatial scales of a few $\mathrm{km}$ to tens of $\mathrm{km}$, across which GPS propagation path moves, and can be correlated to scintillation occurrence (Beach and Kintner 1999), therefore, to bubble occurrence. Here we define $\mathrm{ROTI}_{30}$ as an average of six successive ROTIs for $30 \mathrm{~min}$. First, for each station a noise level 
of $\mathrm{ROTI}_{30}$ on a given day was calculated by averaging the $\mathrm{ROTI}_{30}$ values between local noon and sunset, during which plasma bubbles are believed to disappear. Second, the noise level $(N)$ thus determined was subtracted from $\mathrm{ROTI}_{30}$ between local sunset and midnight to know the disturbances of $\mathrm{ROTI}_{30}$ at night. Third, the number of cases, for which the $\mathrm{ROTI}_{30}-N$ value exceeds a threshold of 0.06 TECU min $^{-1}$, was counted up. This threshold was chosen by trial and error to pick up plasma bubble events as many as possible and also to abandon noise-like $\mathrm{ROTI}_{30}$ fluctuations. Fourth, if this number was more than one, we regarded the day as "bubble day", i.e. the day on which plasma bubbles appeared. Finally, to estimate the bubble occurrence rate (in \%) of a particular day, the number of bubble days out of 91 days ( \pm 45 days of that day) was counted up, and then divided by 91 . This process provides a smoothed daily variation of the occurrence rate, and can highlight seasonal variability of that, though it is impossible to know day-to-day variability of bubble occurrences. It is noted that the GPS scintillations were observed, more or less, at Kototabang on the bubble days at PIMO, NTUS, and SAMP.

The bubble occurrence rates thus inferred at the five GPS stations and the scintillation occurrences at Kototabang (Fig. 4) in 2003 are shown in Fig. 5. This figure compares the scintillations due to irregularities with a scale length of about $400 \mathrm{~m}$ and the TEC fluctuations with scale lengths of a few $\mathrm{km}$ to tens of $\mathrm{km}$. As can be clearly seen, when the scintillations are enhanced (subside), the bubble occurrence rates

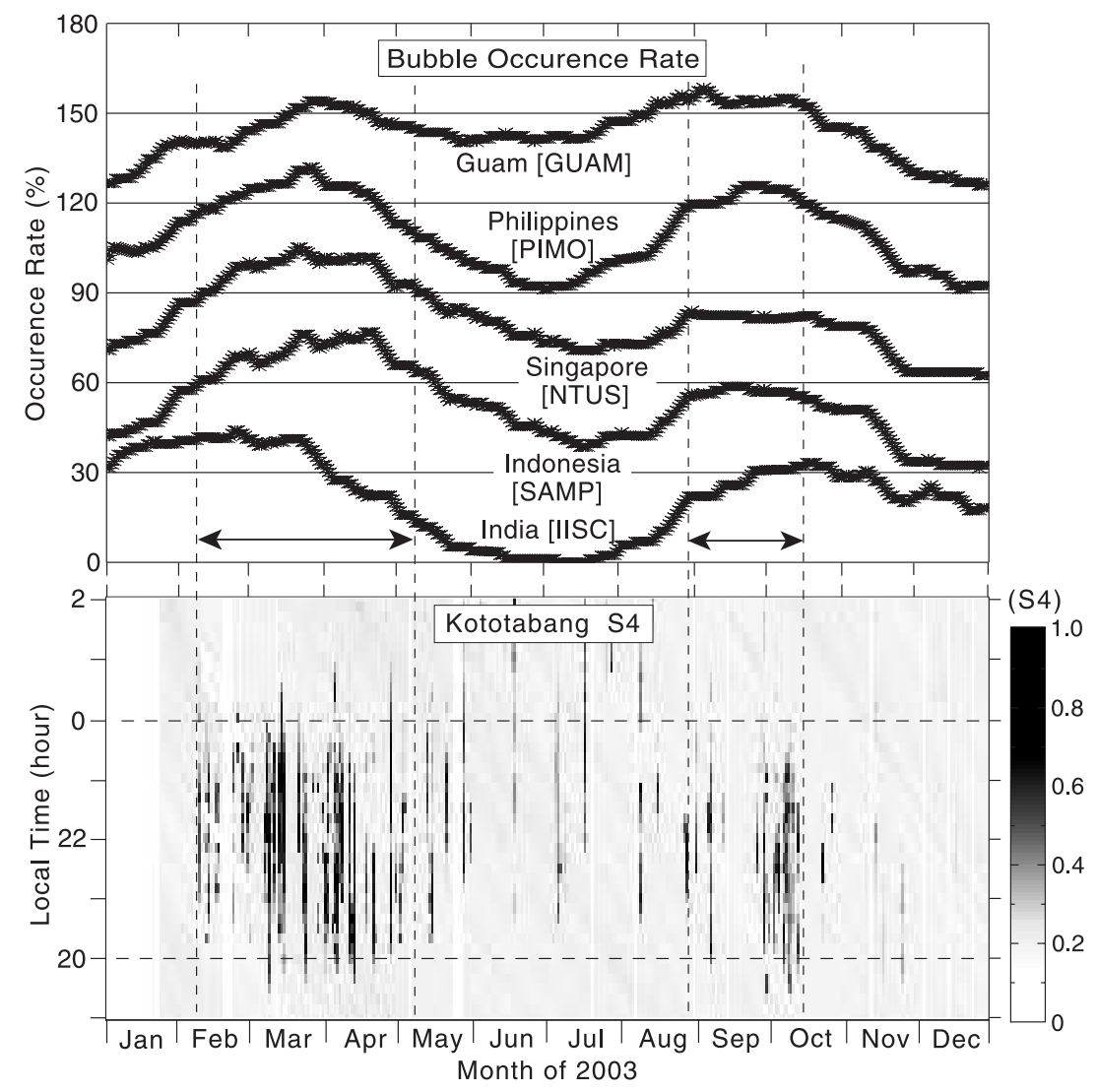

Fig. 5. (Top) Stack plot of daily occurrence rate of plasma bubbles in 2003 inferred from TEC data at five IGS stations. (Bottom) Variations of GPS scintillation index $S_{4}$ in day-local time coordinates observed at Kototabang in 2003 (see Fig. 4). Vertical white portions in the bottom panel represent no observations due to instrumental problem. Periods of the scintillation occurrences are marked by horizontal arrows. 
at five stations are generally high (low), which suggests that the scintillation occurrence is closely related to the bubble occurrence. The correlation between two parameters is fairly excellent, in particular, for PIMO, NTUS, and SAMP close $(<2500 \mathrm{~km})$ to Kototabang during February-April, but is not good for GUAM and IISC because of the well-known longitudinal variability of the bubble occurrences (e.g., Burke et al. 2004). The occurrence rates for NTUS and SAMP are higher in February-April than September-October, in line with the higher scintillation activity in February-April.

\section{Scintillations and tropospheric disturbances}

In the above we have briefly reviewed the observations of MSTIDs over the equator and geomagnetic-conjugate plasma bubbles, and have newly presented the scintillation activity over Kototabang that can be surely associated with plasma bubbles. The appearances of MSTIDs and bubbles are closely related to electron density fluctuations in the $F$ region with spatial scales of $100-1000 \mathrm{~km}$ (or more). Then, what are the origins of these fluctuations?; in other words, what seeds the fluctuations? One candidate is equatorward-propagating, largescale ionospheric disturbances due to substorm activity at high-latitudes. However the substorm occurrence is highly sporadic, and cannot always be the origin of plasma fluctuations over the equator. Another candidate is AGWs from below. As a first step to explore this possibility, we try to compare statistically the scintillation activity over Kototabang and black body temperature $\left(T_{b b}\right)$ (often called the "cloud-top temperature") of the Earth inferred from OLR (Outgoing Long wave Radiation) data that were continuously monitored from geostationary meteorological satellites (GMS-5 before 21 May 2003 and GOES-9 after 22 May 2003), in hope that AGWs inducing ionospheric plasma disturbances may be launched upward from active regions in the troposphere (e.g., Röttger 1977, 1981; Hocke and Tsuda 2001; Tsuda and Hocke 2004). For example, Tsuda et al. (2000) and Tsuda and Hocke (2004) showed that AGW energy in the stratosphere inferred from GPS/MET data is enhanced, in particular, over Indonesia where $T_{b b}$ is low (cold).

Figure 6 shows daily variations of $T_{b b}$ and $S_{4}$ at Kototabang in equinoctial months in 2003 and 2004. Each $T_{b b}$ plot covers longitudes between $70^{\circ}$ and $102^{\circ} \mathrm{E}$. The $T_{b b}$ values averaged over $2^{\circ} \mathrm{S}-2^{\circ} \mathrm{N}$ and $0000-2400 \mathrm{UT}$ are plotted in the figure. The cloud clusters with eastward movement from the Indian Ocean to Sumatra can be seen more or less in all the seasons. The organized temperature structures over the Indian Ocean are usually disturbed at around $100^{\circ} \mathrm{E}$ due to high mountains in Sumatra. We observe in Fig. 6a that when the scintillations occur between 2000 and $2400 \mathrm{LT}$, the $T_{b b}$ values are higher than, say, $270 \mathrm{~K}$ somewhere between $70^{\circ}$ and $95^{\circ} \mathrm{E}$ : for example, the scintillations on days 66-75, 95-99, and 101-104 are correlated to high $T_{b b}$ at $80^{\circ}-96^{\circ} \mathrm{E}$. However this is not always true for other scintillation events; the $T_{b b}$ values for the scintillations on days 83-84 are low anywhere, and those for the scintillations on days $92-93$ are high at $70^{\circ}-82^{\circ} \mathrm{E}$ but low at $82^{\circ}-98^{\circ} \mathrm{E}$. Such correlations are also discerned in Figs. 6b, 6c, and 6d.

Next we examine quantitatively the correlation between the two parameters. To this end, cross correlation coefficients $(R)$ between $S_{4}$ (averaged over 2200-2300 LT and 2300-2400 LT) and $T_{b b}$ (averaged over 0000-2400 UT and $1.0^{\circ} \mathrm{NS} \times 1.0^{\circ} \mathrm{WE}$ box) at $0^{\circ} \mathrm{N}$ at five longitudes were calculated for four seasons in 2003 and 2004. The results are displayed in Fig. 7. In Fig. 7a the $R$ values for the period of 1 March-30 April are positive (i.e. high $S_{4}$ for high $T_{b b}$ ), and decrease from $+0.29-+0.41$ at $80^{\circ}$ and $85^{\circ} \mathrm{E}$ to $0.01-+0.17$ at $95^{\circ} \mathrm{E}$. This result indicates that the scintillation occurrences over Kototabang may be affected by the tropospheric activity at longitudes of $80^{\circ}-90^{\circ} \mathrm{E}$, i.e. $10^{\circ}-20^{\circ}$ west of Kototabang. We think that the $R$ values at $100^{\circ}$ are meaningless because, as can be seen in all the figures in Fig. 6, the $T_{b b}$ values near Kototabang usually fluctuate due to high mountains in Sumatra. For the period of 2 September-1 November, the $R$ values are negative (i.e. high $S_{4}$ for low $T_{b b}$ ) in general, and are highest $(-0.39)$ at $95^{\circ} \mathrm{E}$, suggesting that contrary to the March-April case, the tropospheric activity at longitudes close to Kototabang might induce the scintillations. Contrary to the clear correlations seen in Fig. 7a, the correlations for two seasons in 2004 shown in Fig. $7 \mathrm{~b}$ are poor, though the $R$ values peak at $85^{\circ} \mathrm{E}$ $(+0.21)$ and $90^{\circ} \mathrm{E}(-0.22)$. 

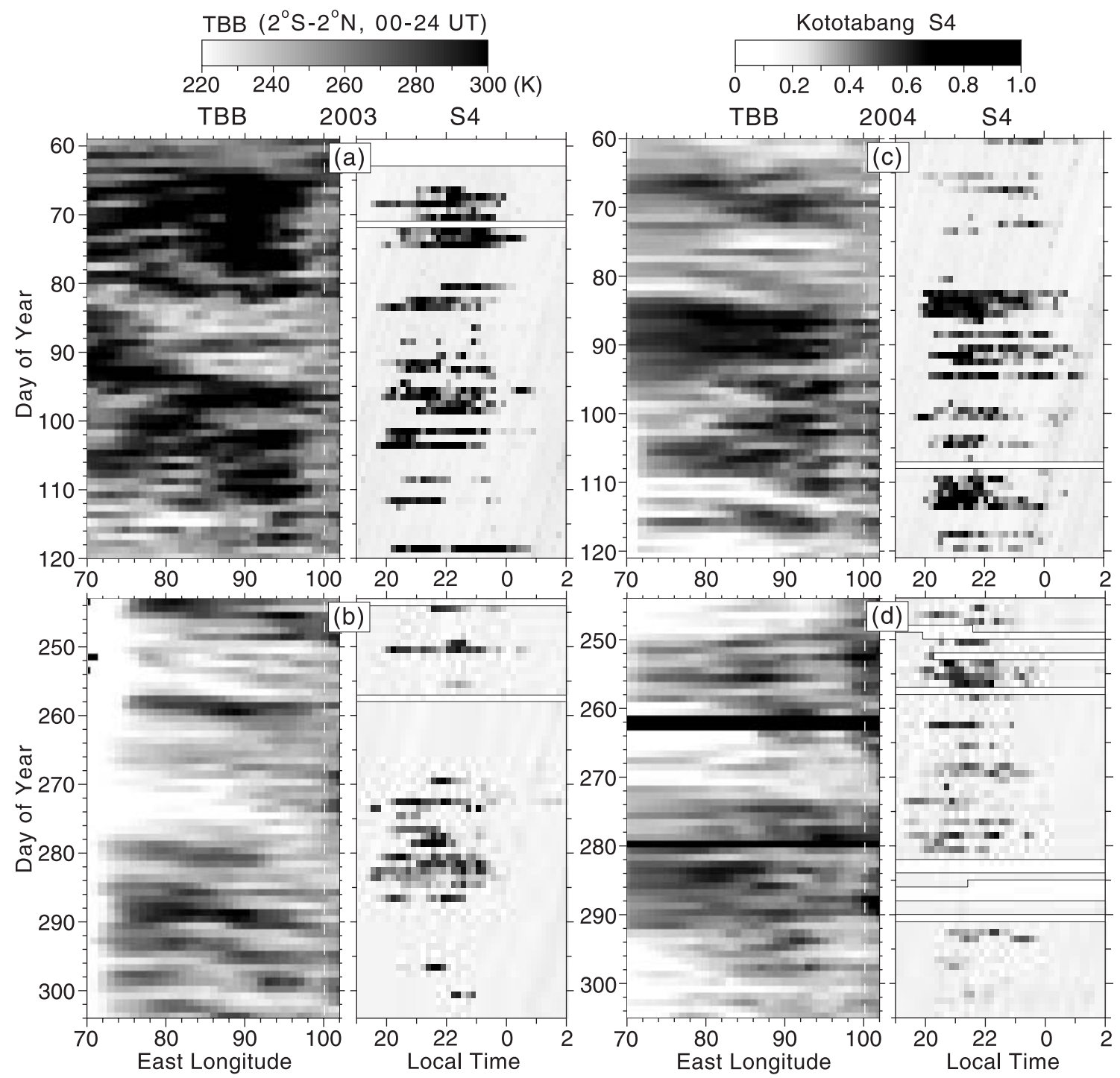

Fig. 6. Daily variations of black body temperature $T_{b b}$ (averaged over $2^{\circ} \mathrm{S}-2^{\circ} \mathrm{N}$ and 24 hours in UT) and GPS scintillation index $S_{4}$ : (a) 1 March (day 60)-30 April (day 120) 2003, (b) 1 September (day 244)-31 October (day 304) 2003, (c) 29 February (day 60)-29 April (day 120) 2004, and (d) 1 September (day 245)-30 October (day 304) 2004. Vertical dashed-line in each $T_{b b}$ plot indicates the longitude of Kototabang $\left(100.32^{\circ} \mathrm{E}\right)$. Horizontal white portions in each $S_{4}$ plot represent no observations due to instrumental problem.

To know spectral components of the $T_{b b}$ and $S_{4}$ variations, we made a Fourier analysis of both parameters. $T_{b b}$ (averaged over 0000$2400 \mathrm{UT}$ and $1.0^{\circ} \mathrm{NS} \times 1.0^{\circ} \mathrm{WE}$ box $)$ at six geographical locations and $S_{4}$ (averaged over 2000-0100 LT) were used in the calculations. The results for four seasons in 2003 and 2004 are shown in Figs. 8a, 8c, 8e, and 8g for periods of 2-15 days: these figures are enlarged in Figs.
$8 \mathrm{~b}, 8 \mathrm{~d}, 8 \mathrm{f}$, and $8 \mathrm{~h}$ for periods of $2-6$ days, respectively. In Fig. 8a, the 13-day $S_{4}$ component is well correlated to the enhanced 13-day $T_{b b}$ components at $\left(0^{\circ} \mathrm{N}, 80^{\circ} \mathrm{E}\right)$ and $\left(0^{\circ} \mathrm{N}, 90^{\circ} \mathrm{E}\right)$. The predominant peak with a period of 7 days of $S_{4}$ coincides well with that of $T_{b b}$ at $\left(0^{\circ} \mathrm{N}\right.$, $\left.90^{\circ} \mathrm{E}\right)$. This 7-day period is close to the predominant 8-day period of $T_{b b}$ at $\left(5^{\circ} \mathrm{N}, 80^{\circ} \mathrm{E}\right)$ and $\left(10^{\circ} \mathrm{N}, 80^{\circ} \mathrm{E}\right)$. In Fig. 8b, the 5.8-day and 2.3- 


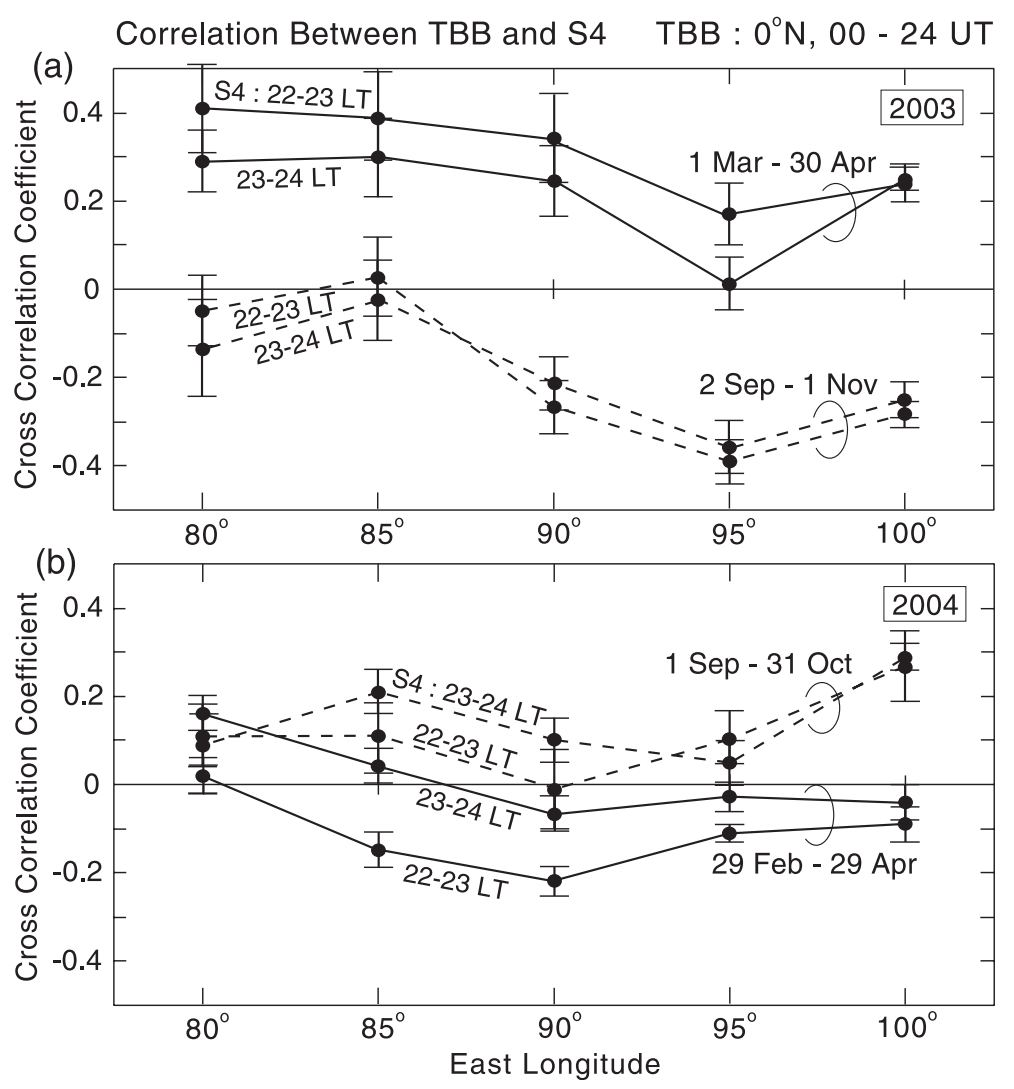

Fig. 7. Cross correlation coefficients between GPS scintillation index $S_{4}$ (averaged over 2200-2300 and 2300-2400 LT) and $T_{b b}$ (averaged over 0000-2400 UT and $1.0^{\circ} \mathrm{NS} \times 1.0^{\circ} \mathrm{WE}$ box) at $0^{\circ} \mathrm{N}$ at five longitudes in two seasons in (a) 2003 and (b) 2004. Mean square error for each coefficient is shown by a vertical bar.

2.5-day components of $S_{4}$ have counterparts in $T_{b b}$ at $\left(5^{\circ} \mathrm{N}, 90^{\circ} \mathrm{E}\right)$ and $\left(10^{\circ} \mathrm{N}, 80^{\circ} \mathrm{E}\right)$, and $\left(0^{\circ} \mathrm{N}\right.$, $\left.80^{\circ} \mathrm{E}\right)$, respectively. Such a coincidence between $S_{4}$ and $T_{b b}$ is also discerned for periods of $8,4.6$, 3.5, 3, and 2.4 days in Figs. $8 \mathrm{c}$ and $8 \mathrm{~d}$, and for periods of $9,5.8,4.2-4.5$, and 3 days in Figs. 8e and 8f. In Fig. 8g, the 13- and 8-day components of $S_{4}$ have counterparts in $T_{b b}$ at $\left(10^{\circ} \mathrm{N}\right.$, $\left.80^{\circ} \mathrm{E}\right)$ and $\left(5^{\circ} \mathrm{N}, 90^{\circ} \mathrm{E}\right)$, and $\left(5^{\circ} \mathrm{N}, 80^{\circ} \mathrm{E}\right)$, respectively. Finally, in Fig. $8 \mathrm{~h}$ the 4 - and 4.6-day components of $S_{4}$ are correlated to those of $T_{b b}$ at $\left(10^{\circ} \mathrm{N}, 90^{\circ} \mathrm{E}\right)$ and $\left(10^{\circ} \mathrm{N}, 80^{\circ} \mathrm{E}\right)$, respectively. Thus, we find from Fig. 8 that some predominant periods seen in $S_{4}$ have counterparts in the $T_{b b}$ fluctuations, and that some predominant periods appearing in $T_{b b}$ do not always have counterparts in $S_{4}$. For example, Takahashi et al. (2005) have recently found 2- and 4day period oscillations of the equatorial iono- spheric bottom height (h'F) and mesospheric airglow intensity, which suggests the existence of planetary-scale waves in the ionosphere. These periods are also found in the bubble and scintillation occurrences in Fig. 8.

\section{Summary and discussion}

The results are summarized as follows:

1. Plasmas in the equatorial ionosphere over Indonesia are often disturbed due to AGWs. Wavy airglow structures in the bottomside $F$ region, categorized as MSTIDs, were detected with the Kototabang 630-nm imager. They exhibit a high occurrence rate in May and June, are observed within and in the south of the $F$ region equatorial anomaly crest, and have, on the average, a phase velocity of $300 \mathrm{~m} \mathrm{~s}^{-1}$ toward the south, a period of $40 \mathrm{~min}$, and a wavelength of $700 \mathrm{~km}$ (Shiokawa et al. 2005). 


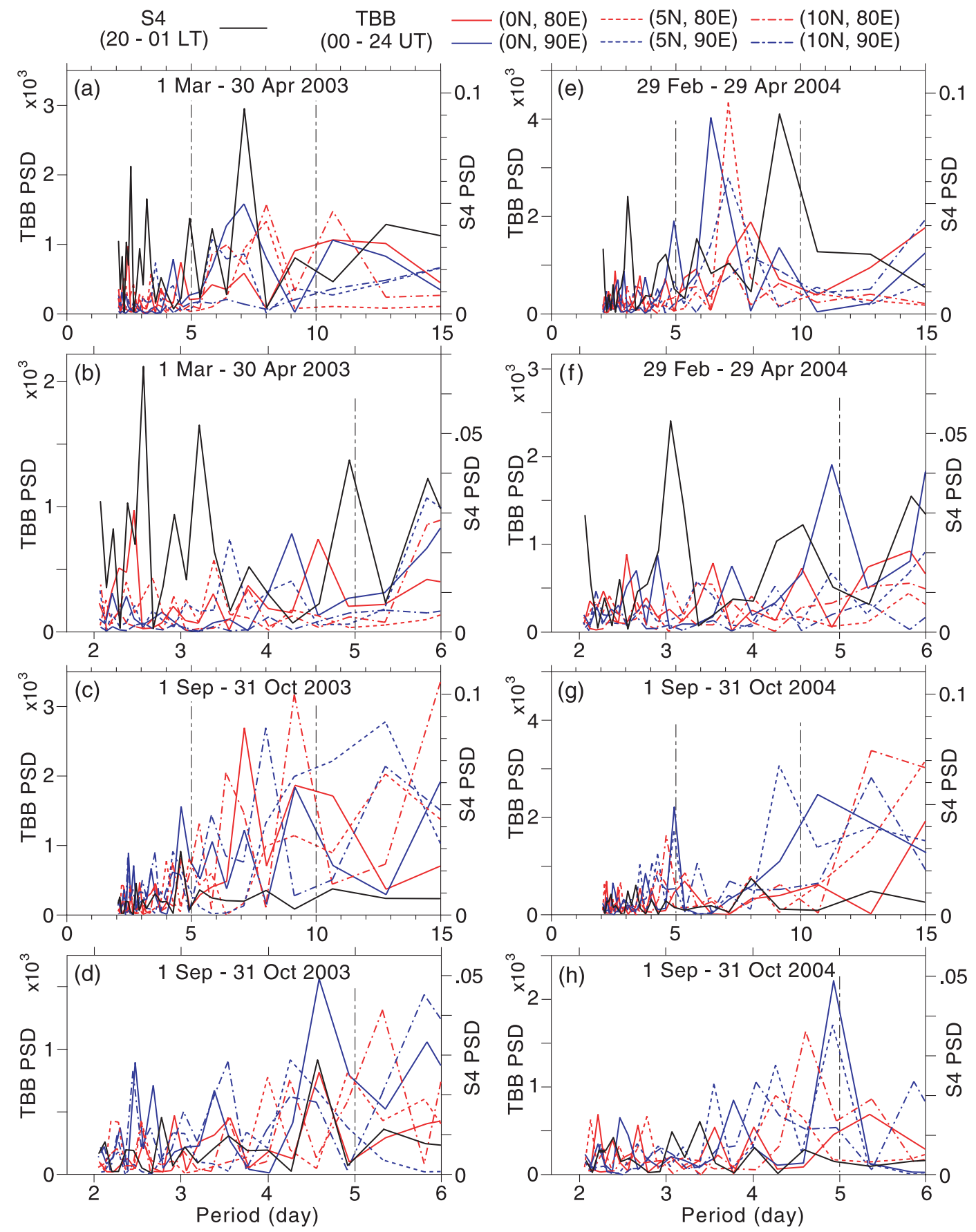

Fig. 8. Periodgrams of GPS scintillation index $S_{4}$ (averaged over 2000-0100 LT) and $T_{b b}$ (averaged over $0000-2400 \mathrm{UT}$ and $1.0^{\circ} \mathrm{NS} \times 1.0^{\circ} \mathrm{WE}$ box) at six geographical locations for four seasons: (a) and (b) 1 March-30 April 2003, (c) and (d) 1 September-31 October 2003, (e) and (f) 29 February29 April 2004, and (g) and (h) 1 September-31 October 2004. 
2. The equatorial ionosphere is also susceptible to the disturbances with east-west scales of 100-1000 km. In particular, nighttime plasma bubbles moving to the east at $\sim 100 \mathrm{~m} \mathrm{~s}^{-1}$ have a scale of about $100 \mathrm{~km}$ with spacings of 200$250 \mathrm{~km}$, and are embedded within 1000-km scale plasma structures. Plasma bubbles can be simultaneously detected at lower midlatitudes in southern and northern hemispheres that are connected by the geomagnetic field line, and are very identical in appearance in the both hemispheres (Otsuka et al. 2002; Shiokawa et al. 2004; Ogawa et al. 2005). The former fact strongly suggests that well-developed bubbles can extend up to $1800 \mathrm{~km}$ altitude over the magnetic equator.

3. Two-year observations of GPS scintillations at Kototabang caused by FAIs with a spatial scale of about $350 \mathrm{~m}$ indicate that the scintillations appear from sunset to midnight (2000-0100 LT) in equinoctial months, consistent with previous observations. Such a seasonal variation is also recognized in the statistical study of bubble occurrences using GPS-TEC data from the Philippines, Singapore, and Indonesia. This result strongly suggests that FAIs causing scintillations are collocated within and around bubbles. Thus we can know temporal, daily, and seasonal variations of bubble occurrence from the scintillation observations.

4. As a first step to investigate possible relationship between bubble (scintillation) occurrence and AGW activity, we have examined correlation between scintillation index $S_{4}$ and $T_{b b}$. We regard the $T_{b b}$ variation as a proxy of AGW activity in the troposphere. The results indicate that in March-April 2003, the cross correlation coefficients between $S_{4}$ and $T_{b b}$ at the equator are high and positive (about +0.4 ) for $T_{b b}$ at $80^{\circ}-85^{\circ} \mathrm{E}$, about $1500-2000 \mathrm{~km}$ west of Sumatra, and that in September-October 2003, they are high and negative (about -0.4) for $T_{b b}$ at $95^{\circ} \mathrm{E}$. The coefficients in 2004 are poor in general. Temporal variations of $S_{4}$ with periods of a few-13 days, perhaps due to planetary waves, have surely counterparts in $T_{b b}$ variations observed near the equator at $80^{\circ}-90^{\circ} \mathrm{E}$. However, some predominant periods appearing in $T_{b b}$ do not always have counterparts in $S_{4}$.

Origins of AGWs inducing the wavy $630-\mathrm{nm}$ airglow structures (item 1) are still unknown, but one of them is attributable to tropospheric activity. Reasons of high occurrence of the structures in May and June is also unclear. As is well known, upward propagation of AGWs from below is highly controlled by mesospheric and lower thermospheric conditions, and some AGWs saturate and dissipate there before arriving at higher altitudes. Seasonal variation of these conditions together with seasonal change of the thermosphere and ionosphere may bring about the high occurrence rate of the airglow structures in May and June. The airglow structures propagate mostly southward (poleward). However, as noted in section 2.1, this does not necessarily mean that AGWs in the thermosphere always propagate southward. Zonally-propagating AGWs cannot induce wavy electron density (airglow) structures in the $F$ region.

As to item 2, bubbles are believed to be generated through the R-T plasma instability in the $F$ region. Although the electrodynamics associated with bubbles have been well investigated for long years, we do not know what seeds this instability, and why the bubbles have spatial scale lengths of 100-250 km. We suppose that AGWs from below play a role in seeding bubbles and also in producing the $1000-\mathrm{km}$ scale structures.

The GPS scintillations (bubbles) appear at night in equinoctial months (item 3). The AGW activity seen in the $630-\mathrm{nm}$ all-sky images, however, is highest in May and June (item 1). If AGWs initiate directly the bubbles, the bubble occurrences may be also highest in May and June, but not in equinoctial months. Many thermospheric and ionospheric parameters depending on season are known to contribute to the bubble generation. Thermospheric winds, which are believed to be important factor for the bubble generation, interact with AGWs to modify these, and control the R-T instability growth (e.g., Maruyama and Matuura 1984; Sultan 1996). Ionospheric conditions like northsouth asymmetry of the $F$ region, evening enhancement of $F$ region electric field, electrical conductivities in the $E$ and $F$ region (e.g., Zalesak et al. 1982), etc. are also important for the initiation of the instability. As a result, the bubble occurrence has predominant peaks in equinoctial months in contrast to the high occurrence of AGWs in May and June. 
According to the above results and previous observations, we speculate the following rough scenario for processes seeding plasma bubbles (therefore, scintillations). First, AGWs with horizontal scales of 100-1000 km (or more) are launched from convectively-active regions accompanied by spatial and temporal variations of $T_{b b}$. When AGWs go up to the thermosphere through the mesosphere, the ionospheric plasmas are modulated due to ion-neutral collisions to produce wavy electron density structures like MSTIDs. These structures, which may be amplified via the spatial resonance mechanism (Whitehead 1971), together with an eastward electric field can initiate the R-T instability in the bottomside $F$ region near the solar terminator (e.g., Yokoyama et al. 2004). When this instability works well, bubbles are born and then develop upward (accordingly, toward lower midlatitudes) while drifting to the east at about $100-150 \mathrm{~m} \mathrm{~s}^{-1}$ due to $\mathbf{E} \times \mathbf{B}$ plasma drift, as observed with HF-VHF radars (e.g., Röttger 1973; Woodman and LaHoz 1976; Kelley et al. 1981; Tsunoda and White 1981; Hysell et al. 1990; Fukao et al. 2004). The bubbles born near the terminator cross over Kototabang at 2000 LT at the earliest to cause scintillations of GPS signals, and move further to the east beyond the GPS FOV. If some bubbles cross over Kototabang successively, scintillations continue for long hours (see Fig. 4). From this scenario, we expect that the scintillation occurrences observed at Kototabang can be related to the tropospheric activities at around $80^{\circ}-95^{\circ}$ near the equator, which is in line with the high correlations between $T_{b b}$ and $S_{4}$ for the 2003 case in Fig. 7. Hocke and Tsuda (2001) found that sporadic $E$ and other ionospheric irregularities of the mesosphere and lower thermosphere over the equator are highly correlated to AGW activity in the lower stratosphere and to tropical convection zones. Tsuda and Hocke (2004) showed that AGW energy in the stratosphere is enhanced over Indonesia where $T_{b b}$ is low.

The actual processes, however, are not so simple as described above, but more complicated. AGWs from below cannot always arrive at the $F$ region altitudes. Ionospheric and thermospheric conditions controls the initiation of the R-T instability. Thus, while AGWs can trigger the R-T instability, we cannot expect a full correlation between the scintillation (bubble) occurrence and tropospheric activity, as exemplified partly in this paper.

We have used routinely-obtained $T_{b b}$ data as a proxy of the tropospheric activity. Röttger (1977) adopted other meteorological data (rain fall) to investigate the relationship between ionospheric disturbances and tropospheric activity in the intertropical convergence zone, and concluded that penetrative cumulus convection is the most likely generation mechanism of the gravity waves exciting TIDs (see also Röttger 1981). In the future, we need more sophisticated analyses of simultaneous ionospheric, mesospheric, and tropospheric data to know the dynamical couplings between the ionosphere/thermosphere and troposphere over Kototabang. Numerical simulations under realistic conditions are also helpful to understand the couplings among the troposphere, stratosphere, mesosphere, and thermosphere/ ionosphere in a quantitative manner (e.g., Horinouchi et al. 2002). From model calculations, Vadas and Fritts (2004) have suggested that AGWs with sufficiently large vertical wavelengths and group velocities excited by mesoscale convective complexes at equatorial latitudes can penetrate to the thermosphere, possibly contributing to the seeding of equatorial spread- $F$ (bubble).

\section{Acknowledgments}

Optical and GPS observations at the EAR site in Kototabang have been conducted in collaboration with RISH of Kyoto University and LAPAN of Indonesia since September 2002. We deeply appreciate the staff of LAPAN for their extensive collaborations to the observations. The all-sky imager at Darwin is operated at the ionospheric station of the IPS Radio and Space Services, Australia. The GPS-TEC data were kindly supplied by International GNSS Service (IGS) and Scripps Orbit and Permanent Array Center (SOPAC). We appreciate M. Hattori for his help to data analysis. This work is supported by Grant-in-Aid for Scientific Research $(11440145,13573006)$ and on Priority Area-764 (13136201) of the Ministry of Education, Culture, Sports, Science and Technology of Japan, and partly by the 21st Century COE Program "Dynamics of the Sun-Earth-Life Interactive System (SELIS)" of Nagoya University, Japan. 


\section{References}

Aarons, J., J.A. Klobuchar, H.E. Whitney, J. Austen, A.L. Johnson, and C.L. Rino, 1983: Gigahertz scintillations associated with equatorial patches. Radio Sci., 18, 421-434.

Abdu, M.A., 2004: Outstanding problems in the equatorial ionosphere-thermosphere electrodynamics relevant to spread F. J. Atmos. Solar-Terr. Phys., 63, 869-884.

Basu, Su., S. Basu, J.P. MuClure, W.B. Hanson, and H.E. Whitney, 1983: High resolution topside in situ data of electron densities and $\mathrm{VHF} / \mathrm{GHz}$ scintillations in the equatorial region. J. Geophys. Res., 88, 403-415.

and - 1985: Equatorial scintillations: advances since ISEA-6. J. Atmos. Terr. Phys., 47, 753-768.

Basu, S., E. MacKenzie, and Su. Basu, 1988: Ionospheric constraints of $\mathrm{VHF} / \mathrm{UHF}$ communications links during solar maximum and minimum periods. Radio Sci., 23, 363-378.

Beach, T.L., and P.M. Kintner, 1999: Simultaneous Global Positioning System observations of equatorial scintillations and total electron content fluctuations. J. Geophys. Res., 104, 22,553-22,565.

Beer, T., 1973: Spatial resonance in the ionosphere. Planet. Space Sci., 21, 297-307.

Burke, W.J., C.Y. Huang, L.C. Gentile, and L. Bauer, 2004: Seasonal-longitudinal variability of equatorial plasma bubbles. Ann. Geophys., 22, 3089-3098.

Fukao, S., Y. Ozawa, T. Yokoyama, M. Yamamoto, R.T. Tsunoda, 2004: First observations of the spatial structure of $F$ region 3-m-scale fieldaligned irregularities with Equatorial Atmosphere Radar in Indonesia. J. Geophys. Res., 109, A02304, doi:10.1029/2003JA010096.

- 2006 : Coupling processes in the equatorial atmosphere (CPEA): A project overview. J. Meteor. Soc. Japan, this issue.

Hocke, K. and T. Tsuda, 2001: Gravity waves and ionospheric irregularities over tropical convection zones observed by GPS/MET radio occultation. Geophys. Res. Lett., 28, 28152818.

Hooke, W.H., 1970: The ionospheric response to internal gravity waves, 1 . The $F_{2}$ region response. J. Geophys. Res., 75, 5535-5544.

Horinouchi, T., Nakamura, T., and Kosaka, J., 2002: Convectively generated mesoscale gravity waves simulated throughout the middle atmosphere. Geophys. Res. Lett., 29(21), 2007, doi: 10.1029/2002GL016069, 2002.

Hysell, D.L., M.C. Kelley, W.E. Swartz, and R.F. Woodman, 1990: Seeding and layering of equa- torial spread $F$ by gravity waves. J. Geophys. Res., 95, 17,253-17,260.

Kelley, M.C., M.F. Larsen, C. LaHoz, and J.P. McClure, 1981: Gravity wave initiation of equatorial spread F: A case study. J. Geophys. Res., 86, 9087-9100.

1989: The Earth's Ionosphere. Academic Press, San Diego.

, J.J. Makela, B.M. Ledvina, and P.M. Kintner, 2002: Observations of equatorial spread- $F$ from Haleakala, Hawaii. Geophys. Res. Lett., 29(20), 2003, 10.1029/2002GL015509.

—, L.J. Paxton, F. Kamalabadi, J.M. Comberiate, and H. Kil, 2003: The first coordinated ground-based and space-based optical observations of equatorial plasma bubbles. Geophys. Res. Lett., 30(14), 1766, doi:10.1029/ 2003 GL017301.

Lin, C.S., T.J. Immel, H.C. Yeh, S.B. Mende, and J.L. Burch, 2005: Simultaneous observations of equatorial plasma depletion by IMAGE and ROCSAT-1 satellites. J. Geophys. Res., 110, A06304, doi:10.1029/2004JA010774.

Maruyama, T. and N. Matuura, 1984: Longitudinal variability of annual changes in activity of equatorial spread $F$ and plasma bubbles. $J$. Geophys. Res., 89, 10,903-10,912.

McClure, J.P., S. Singh, D.K. Bamgboye, F.S. Johnson, and H. Kil, 1998: Occurrence of equatorial $F$ region irregularities: Evidence for tropospheric seeding. J. Geophys. Res., 103, 29,11929,135 .

Ogawa, T., E. Sagawa, Y. Otsuka, K. Shiokawa, T.J. Immel, S.B. Mende, and P. Wilkinson, 2005: Simultaneous ground- and satellite-based airglow observations of geomagnetic conjugate plasma bubbles in the equatorial anomaly. Earth Planets Space, 57, 385-392.

Otsuka, Y., K. Shiokawa, T. Ogawa, and P. Wilkinson, 2002: Geomagnetic conjugate observations of equatorial airglow depletions. Geophys. Res. Lett., 29(15), 10.1029/2002GL015347.

, _ , T. Yokoyama, M. Yamamoto, and S. Fukao, 2004: Spatial relationship of equatorial plasma bubbles and field-aligned irregularities observed with an all-sky airglow imager and the Equatorial Atmosphere Radar. Geophys. Res. Lett., 31, L20802, doi:10.1029/ 2004 GL020869.

-, K. Shiokawa, and T. Ogawa, 2006: Equatorial ionospheric scintillations and zonal irregularity drifts observed with closely-spaced GPS receivers in Indonesia. J. Meteor. Soc. Japan, this issue.

Oya, H., T. Takahashi, and S. Watanabe, 1986: Observation of low latitude ionosphere by the im- 
pedance probe on board the Hinotori satellite. J. Geomag. Geoelectr., 38, 111-123.

Röttger, J., 1973: Wave-like structures of large-scale equatorial spread- $F$ irregularities. J. Atmos. Terr. Phys., 35, 1195-1206.

, 1977: Travelling disturbances in the equatorial ionosphere and their association with penetrative cumulus convection. J. Atmos. Terr. Phys., 39, 987-998.

, 1981: Equatorial spread- $F$ by electric fields and atmospheric gravity waves generated by thunderstorms. J. Atmos. Terr. Phys., 43, 453462.

Sagawa, E., T. Maruyama, T.J. Immel, H.U. Frey, and S.B. Mende, 2003: Global view of the nighttime low-latitude ionosphere by the IMAGE/FUV $135.6 \mathrm{~nm}$ observations. Geophys. Res. Lett., 30(10), 1534, doi:10.1029/ 2003 GL017140.

Shiokawa, K., Y. Otsuka, T. Ogawa, and P. Wilkinson, 2004: Time evolution of high-altitude plasma bubbles imaged at geomagnetic conjugate points. Ann. Geophysicae, 22, 3137-3143.

—, 2005: Quasi-periodic southward-moving waves in 630-nm airglow images in the equatorial thermosphere. J. Geophys. Res., in press.

—, S. Suzuki, Y. Otsuka, T. Ogawa, T. Nakamura, M.G. Mlynczak, and J.M. Russell III, 2006: A multi-instrument measurement of a mesospheric front-like strucuture at the equator. J. Meteor. Soc. Japan, this issue.

Singh, S., F.S. Johnson, and R.A. Power, 1997: Gravity wave seeding of equatorial plasma bubbles. J. Geophys. Res., 102, 7399-7410.

Sultan, F.J., 1996: Linear theory and modeling of the Rayleigh-Taylor instability leading to the occurrence of equatorial spread F. J. Geophys. Res., 101, 26,875-26,891.

Takahashi, H., L.M. Lima, C.W. Wrasse, M.A. Abdu, I.S. Batista, D. Gobbi, R.A. Buriti, and P.A. Ba- tista, 2005: Evidence on 2-4 day oscillations of the equatorial ionosphere h'F and mesospheric airglow emissions. Geophys. Res. Lett., 32, L12102, doi:10.1029/2004GL022318.

Tsuda, T., M. Nishida, C. Rocken, and R.H. Ware, 2000: A global morphology of gravity wave activity in the stratosphere revealed by the GPS occultation data (GPS/MET). J. Geophys. Res., 105, 7257-7273.

and Hocke, 2004: Application of GPS radio occultation data for studies of atmospheric waves in the middle atmosphere and ionosphere. $J$. Meteor. Soc. Japan, 82, 419-426.

Tsunoda, R.T. and B.R. White, 1981: On the generation and growth of equatorial backscatter plumes, 1, Wave structure in the bottomside $F$ layer. J. Geophys. Res., 86, 3610-3616.

- 2005: On the enigma of day-to-day variability in the equatorial spread F. Geophys. Res. Lett., 32, L08103, doi:10.1029/2005GL022512.

Vadas, S.L. and D.C. Fritts, 2004: Thermospheric responses to gravity waves arising from mesoscale convective complexes. J. Atmos. SolarTerr. Phys., 66, 781-804.

Whitehead, J.D., 1971: Ionization disturbances caused by gravity waves in the presence of an electrostatic field and background wind. $J$. Geophys. Res., 76, 238-241.

Woodman, R.F. and C. LaHoz, 1976: Radar observations of $F$ region equatorial irregularities. $J$. Geophys. Res., 81, 5447-5466.

Yokoyama, T., S. Fukao, and M. Yamamoto, 2004: Relationship of the onset of equatorial $F$ region irregularities with the sunset terminator observed with the Equatorial Atmosphere Radar. Geophys. Res. Lett., 31, L24804, doi:10.1029/ 2004GL021529.

Zalesak, S.T., S.L. Ossakow, and P.K. Chaturvedi, 1982: Nonlinear equatorial spread $F$ : The effect of neutral winds and background Pedersen conductivity. J. Geophys. Res., 87, 151-166. 